\title{
Can feedback analysis be used to uncover the physical origin of climate sensitivity and efficacy differences?
}

\author{
Vanessa S. Rieger ${ }^{1} \cdot$ Simone Dietmüller $^{1} \cdot$ Michael Ponater $^{1}$
}

Received: 18 July 2016 / Accepted: 29 November 2016 / Published online: 24 December 2016

(C) The Author(s) 2016. This article is published with open access at Springerlink.com

\begin{abstract}
Different strengths and types of radiative forcings cause variations in the climate sensitivities and efficacies. To relate these changes to their physical origin, this study tests whether a feedback analysis is a suitable approach. For this end, we apply the partial radiative perturbation method. Combining the forward and backward calculation turns out to be indispensable to ensure the additivity of feedbacks and to yield a closed forcing-feedbackbalance at top of the atmosphere. For a set of $\mathrm{CO}_{2}$-forced simulations, the climate sensitivity changes with increasing forcing. The albedo, cloud and combined water vapour and lapse rate feedback are found to be responsible for the variations in the climate sensitivity. $\mathrm{An}_{3}$-forced simulation (induced by enhanced $\mathrm{NO}_{\mathrm{x}}$ and $\mathrm{CO}$ surface emissions) causes a smaller efficacy than a $\mathrm{CO}_{2}$-forced simulation with a similar magnitude of forcing. We find that the Planck, albedo and most likely the cloud feedback are responsible for this effect. Reducing the radiative forcing impedes the statistical separability of feedbacks. We additionally discuss formal inconsistencies between the common ways of comparing climate sensitivities and feedbacks. Moreover, methodical recommendations for future work are given.
\end{abstract}

Keywords Climate sensitivity · Efficacy $\cdot$ Radiative feedback $\cdot$ Radiative forcing $\cdot$ Partial radiative perturbation method

Vanessa S. Rieger

vanessa.rieger@dlr.de

1 Deutsches Zentrum für Luft- und Raumfahrt (DLR), Institut für Physik der Atmosphäre, Oberpfaffenhofen, 82230 Weßling, Germany

\section{Introduction}

The radiative forcing concept is fundamental for our understanding of how the climate reacts to an external perturbation (e.g. Shine et al. 1990; Hansen et al. 1997; Myhre et al. 2013). Radiative forcing is the net radiative flux imbalance (defined at top of the atmosphere or at the tropopause) that is induced by a perturbation of e.g. solar radiation or a radiatively active tracer. The climate sensitivity (i.e. the global mean surface temperature change per unit radiative forcing) crucially depends on a number of feedbacks, such as the atmospheric temperature, surface albedo, water vapour and cloud feedback. These feedbacks are only known with limited accuracy (Bony et al. 2006) and at least parts of them are not fully understood. The climate sensitivity as well as the climate feedbacks show a large spread among the climate models. In particular, the cloud feedback has a high uncertainty (e.g. Cess et al. 1989; Ringer et al. 2006; Vial et al. 2013). Global radiative feedback analysis (e.g. Hansen et al. 1984; Colman 2003; Bony et al. 2006; Soden and Held 2006; Andrews et al. 2012; Sherwood et al. 2014) has become a common and important tool in climate research. It is almost indispensable for the purpose of understanding the forcingresponse relation and the sensitivity of our climate system.

The climate sensitivity varies not only in $\mathrm{CO}_{2}$-driven simulations of various climate models, but it also differs between $\mathrm{CO}_{2}$ and non- $\mathrm{CO}_{2}$-driven simulations within the same climate model (e.g. Hansen et al. 1997, 2005; Stuber et al. 2005; Berntsen et al. 2005; Shindell 2014). In these cases, the simple linear relation between radiative forcing $\mathrm{RF}$ and global mean surface temperature response $\Delta \mathrm{T}_{\mathrm{s}}$

$\Delta T_{S}=\lambda \cdot R F$

is not fulfilled because the climate sensitivity $\lambda$ is assumed be independent from the perturbation. This hampers the 
general applicability of the RF concept. To retain its applicability, Hansen et al. (2005) proposed to attribute a specific efficacy parameter for each non- $\mathrm{CO}_{2}$ radiative forcing. The efficacy $r$ is defined via

$\Delta T_{S}=\lambda_{\mathrm{CO}_{2}} \cdot r \cdot R F$

as $\mathrm{r}=\lambda / \lambda_{\mathrm{CO}_{2}}$. The "standard climate sensitivity" $\lambda_{\mathrm{CO}_{2}}$ is obtained by choosing a $\mathrm{CO}_{2}$-driven simulation as the reference simulation.

Various definitions of radiative forcing (Eq. 1), which establish various frameworks of climate sensitivity and efficacies, exist. The effective radiative forcing (ERF) framework, based on conceptual developments initiated by Gregory et al. (2004) and Shine et al. (2003), has been favoured in most recent climate research, i.e. since the 5th IPCC assessment report (AR5, in particular, Myhre et al. 2013). The ERF's merits are twofold. First, "rapid radiative adjustments", directly induced by the radiative forcing, can be cleanly separated from "slow radiative feedbacks", induced by the gradual surface temperature increase. Second, the ERF has helped to limit the diversity of efficacies, in particular for the radiative forcing from absorbing aerosols (Hansen et al. 2005; Shine et al. 2012). It has also improved our understanding of the cloud feedback which contains a large rapid adjustment contribution in $\mathrm{CO}_{2}$-driven climate change simulations (Gregory and Webb 2008; Andrews and Forster 2008; Vial et al. 2013). However, as noted by Myhre et al. (2013), the ERF framework also has an important shortcoming: radiative forcings, rapid forcing adjustments and radiative feedbacks calculated with this method have a much higher statistical uncertainty compared to the classical concept of stratosphere adjusted radiative forcing. This will form a severe problem when moderate forcings, e.g. around $1 \mathrm{Wm}^{-2}$, are used (for example Marvel et al. 2016, supplemental material). Consequently, most studies applying the ERF concept have been performed on the basis of $\mathrm{CO}_{2}$ quadrupling simulations (i.e. a large radiative forcing between 6 and $8 \mathrm{Wm}^{-2}$, e.g. Andrews et al. 2012; Vial et al. 2013; Zelinka et al. 2013). However, in the present paper we also focus on the climate sensitivity of moderate forcings around $1 \mathrm{Wm}^{-2}$. Therefore, we decided to use the classical stratosphere adjusted radiative forcing $\mathrm{RF}_{\mathrm{adj}}$ framework that allows deriving forcing and feedback parameters with less statistical uncertainty (e.g., Dietmüller et al. 2014; Marvel et al. 2016). This decision is additionally justified as variations in efficacies may not generally reduce for non- $\mathrm{CO}_{2}$ forcings under the ERF concept (Shindell 2014; Marvel et al. 2016).

Feedback analysis has been previously applied mainly to explain inter-model climate sensitivity variations. However, it may be used in a similar way to uncover the origin of climate sensitivity and efficacy variations between different forcings (Yoshimori and Broccoli 2008). So far, this has mainly been tried for idealized perturbations (e.g. Stuber et al. 2005). In this paper the potential of a complete feedback analysis to understand climate sensitivity and efficacy difference within one model framework will be explored. We address related methodical issues and give recommendations for optimal use of the analysis method.

\section{Data and methods}

\subsection{Equilibrium climate change simulations}

The set of equilibrium climate change simulations used for this paper is listed in Table 1. All simulations were run with the ECHAM/MESSy Atmospheric Chemistry (EMAC) model (Jöckel et al. 2006). EMAC is a numerical chemistry and climate simulation system that includes sub-models describing tropospheric and middle atmosphere processes and their interaction with oceans, land and human influences. It uses the first version of the Modular Earth Submodel System (MESSy1) to link multi-institutional computer codes. The core atmospheric model is the 5th generation European Centre Hamburg general circulation model (ECHAM5, Roeckner et al. 2006). It is coupled to a mixed layer ocean (MLO) model of $50 \mathrm{~m}$ depth, also including a thermodynamic sea ice model. Equilibrium climate change simulations have been extended over 50 years, of which the first 26 years are not evaluated as they form the spin-up of the MLO. The specific EMAC model setup
Table 1 Key parameters of the equilibrium climate change simulations

\begin{tabular}{llllll}
\hline Simulation & & $\mathrm{RF}_{\text {adj }}\left[\mathrm{Wm}^{-2}\right]$ & $\begin{array}{l}\lambda_{\text {adj }}\left[\mathrm{KW}^{-1} \mathrm{~m}^{2}\right][95 \% \\
\text { confi. }]\end{array}$ & $\mathrm{r}$ \\
\hline $\mathrm{REF}$ & Reference simulation & - & - & - & - \\
$\mathrm{NOX}+\mathrm{CO}$ & $\mathrm{O}_{3}$ change from enhanced $\mathrm{NO}_{\mathrm{X}}$ and $\mathrm{CO}$ & 1.22 & 0.63 & {$[0.57 ; 0.69]$} & 0.86 \\
$1.2 \times \mathrm{CO} 2$ & Increase of $\mathrm{CO}_{2}$ by $75 \mathrm{ppmv}$ & 1.06 & 0.73 & {$[0.67 ; 0.79]$} & 1 \\
$2 \times \mathrm{CO} 2$ & Doubling of $\mathrm{CO}_{2}$ & 4.13 & 0.70 & {$[0.69 ; 0.72]$} & 0.96 \\
$4 \times \mathrm{CO} 2$ & Quadrupling of $\mathrm{CO}_{2}$ & 8.93 & 0.91 & {$[0.90 ; 0.92]$} & 1.25 \\
\hline
\end{tabular}

The stratospheric adjusted radiative forcing $\mathrm{RF}_{\text {adj }}$, the corresponding climate sensitivity $\lambda_{\text {adj }}$ (together with their $95 \%$ confidence intervals) and the efficacies $r$ are listed. The efficacy $r$ is normalized to the $1.2 \times \mathrm{CO} 2$ simulation (see text) 
has been described in Dietmüller (2011) and Dietmüller et al. (2014).

We investigate three $\mathrm{CO}_{2}$ increase simulations as given in Table 1. The reference simulation has a near present-day $\mathrm{CO}_{2}$ mixing ratio of $368 \mathrm{ppmv}$. The $1.2 \times \mathrm{CO} 2$ simulation is forced by a $\mathrm{CO}_{2}$ increase of 75 ppmv yielding a $\mathrm{RF}_{\text {adj }}$ of $1.06 \mathrm{Wm}^{-2}$. Non- $\mathrm{CO}_{2}$-driven simulations mostly have a moderate forcing of around $1 \mathrm{Wm}^{-2}$. Thus, to be able to compare $\mathrm{CO}_{2}$ and non- $\mathrm{CO}_{2}$-driven simulations, we choose the $1.2 \times \mathrm{CO} 2$ simulation to be the standard case. Consequently, the $1.2 \times \mathrm{CO} 2$ simulation has, by definition, an efficacy of 1 . Moreover, we performed simulations with a doubling and a quadrupling of the $\mathrm{CO}_{2}$ concentration $(2 \times \mathrm{CO} 2$ and $4 \times \mathrm{CO} 2$ ) resulting in a forcing of 4.13 and $8.93 \mathrm{Wm}^{-2}$. (Note that the simulations REF, $2 \times \mathrm{CO} 2$ and $4 \times \mathrm{CO} 2$ are identical to simulations REF, $2 * \mathrm{CO} 2_{\text {uncoup }}$ and $4 * \mathrm{CO} 2_{\text {uncoup }}$ described in Dietmüller et al. 2014.) As obvious from Table 1, the resulting stratosphere adjusted climate sensitivities $\lambda_{\text {adj }}$ of the $1.2 \times \mathrm{CO} 2$ and the $2 \times \mathrm{CO} 2$ experiments do not differ on a $5 \%$ statistical significance level, while $4 \times \mathrm{CO} 2$ has a significantly enhanced climate sensitivity.

The non- $\mathrm{CO}_{2}$ simulation $\mathrm{NOX}+\mathrm{CO}$ (Table 1) is driven by an ozone perturbation induced by enhanced $\mathrm{NO}_{\mathrm{x}}$ and $\mathrm{CO}$ surface emissions. For this simulation, an EMAC model setup with interactive chemistry (see Dietmüller et al. 2014, and references therein) has been run twice using prescribed sea surface temperatures: first, with a present-day surface emission inventory and, second, with ninefold increased $\mathrm{NO}_{\mathrm{x}}$ and $\mathrm{CO}$ emissions (Dietmüller 2011). The resulting ozone change pattern (Fig. 1) has then been implemented in the model as a non-interactive ozone increment to force the equilibrium climate change simulation $\mathrm{NOX}+\mathrm{CO}$. This induces a $\mathrm{RF}_{\text {adj }}$ of $1.22 \mathrm{Wm}^{-2}$ (Table 1). The scaling factor nine was chosen to yield a RF of around $1 \mathrm{Wm}^{-2}$, which makes $\mathrm{NOX}+\mathrm{CO}$ comparable to $1.2 \times \mathrm{CO} 2$ (as ranging on a similar RF level). At the same time, the RF level in both simulations was supposed to be large enough to keep the statistical uncertainty of $\Delta \mathrm{T}_{\mathrm{s}}$ and $\lambda$ within reasonable limits (see Sect. 3.4). Note that the ozone distribution in all other simulations (except for NOX $+\mathrm{CO}$ ) is the same as in REF.

\subsection{Partial radiative perturbation analysis}

In order to identify the feedback processes which are responsible for the efficacy differences found in our simulations (Table 1), we use the partial radiative perturbation (PRP) analysis (e.g. Wetherald and Manabe 1988; Colman 2003; Yoshimori and Broccoli 2008; Klocke et al. 2013). We apply this method to the quasi-stationary part of the equilibrium climate change simulations. In this equilibrium phase the radiative forcing is fully balanced by climate feedbacks. Thus, the total feedback parameter $\alpha$ equals the

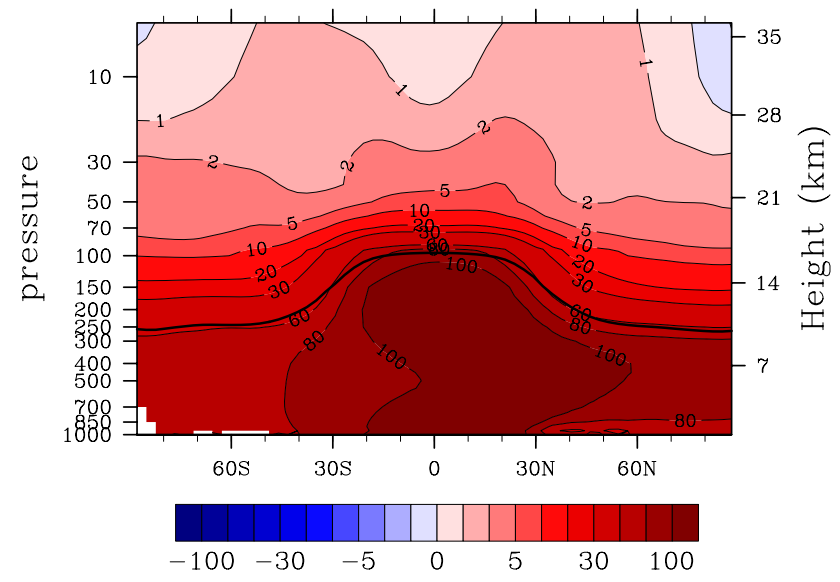

Fig. 1 Ozone increase distribution (displayed as an annual latitudeheight cross section) used as the forcing in the NOX $+\mathrm{CO}$ equilibrium climate change simulation. This ozone change pattern results from enhanced $\mathrm{NO}_{\mathrm{x}}$ and $\mathrm{CO}$ surface emissions in an EMAC simulation with interactive chemistry and prescribed sea surface temperature (see text and Dietmüller 2011). The changes are given in \% of the ozone distribution simulated in REF. In the actual simulations, variation along latitudes and throughout the seasonal cycle are included

negative inverse of the climate sensitivity (Boer and $\mathrm{Yu}$ 2003; Jonko et al. 2013):

$\alpha=-1 / \lambda$

The total feedback parameter $\alpha$ can be regarded as the sum of various individual feedback parameters $\alpha_{i}$. Each $\alpha_{i}$ represents a physically well-defined feedback process controlled by one or few climate variables $\mathrm{x}_{\mathrm{i}}$ :

$\alpha=\sum_{i} \alpha_{i}=\sum_{i}\left(\frac{\Delta_{i} R}{\Delta x_{i}} \cdot \frac{\Delta x_{i}}{\Delta T_{S}}\right)+R E S$

Changes of radiatively active variables $\Delta \mathrm{x}_{\mathrm{i}}$ (e.g. water vapour and surface albedo) induce a change of the radiative flux $\Delta_{\mathrm{i}} \mathrm{R}$. These radiative flux feedbacks amplify or dampen the external radiative forcing, hence modifying the equilibrium surface temperature response $\left(\Delta \mathrm{T}_{\mathrm{s}}\right)$.

The PRP concept is based on the crucial assumption that the feedback processes are sufficiently separable and result in a largely closed radiative balance at the top of the atmosphere (TOA). This implies a small residuum RES in Eq. 4. The validity of this assumption will be put under scrutiny in this paper. Previous work has indicated that RES is near $10 \%$ or more of the feedbacks' sum (Shell et al. 2008; Klocke et al. 2013).

The classical set of feedback parameters $\alpha_{i}$ includes the water vapour feedback $\alpha_{q}$, the surface albedo feedback $\alpha_{A}$, the cloud feedback $\alpha_{C}$, the tropospheric lapse rate feedback $\alpha_{L R}$ and the so-called Planck feedback $\alpha_{\text {pla }}$ (Bony et al. 2006). We explicitly introduce a separate temperature 
related feedback parameter $\alpha_{\text {str }}$ which represents the radiative impact of stratospheric temperature changes. These changes are related to distinct processes fundamentally different from, both, the Planck and the lapse rate feedback. The latter are related to convective mixing of surface and tropospheric temperature changes through the depth of the troposphere. $\alpha_{\text {str }}$ is required to close the balance between forcing and feedbacks in Eq. 3. Previous studies have partly lumped together stratospheric and tropospheric temperature feedbacks (see discussion in Colman 2003). In other studies, mainly addressing $\mathrm{CO}_{2}$ forcing simulations, the stratospheric temperature change has been assumed to be part of $\mathrm{RF}_{\mathrm{adj}}$ or ERF. In these cases, the main part of the stratospheric temperature change is directly induced by the $\mathrm{CO}_{2}$ increase rather than by the slowly evolving sea surface temperature change.

We prefer to apply the PRP analysis over alternative feedback analysis methods like the radiative kernel method (e.g. Soden et al. 2008; Shell et al. 2008; Block and Mauritsen 2013) or feedback calculation involving stratospheric temperature adjustment (Stuber et al. 2001). Despite of their specific merits, these methods seem less appropriate for the goals pursued here. The main problem is that they do not allow a direct calculation of the cloud feedback. Thus, the required check of the residuum RES in Eq. 4 cannot be accomplished. As mentioned, a sufficiently small RES is essential to assess whether efficacy differences may be attributed to changes in certain feedbacks. Moreover, the radiative kernel method includes strict assumptions on linearity which are validated for $\mathrm{CO}_{2}$ forcing but not yet for non- $\mathrm{CO}_{2}$ forcings. Hence, we start the feedback analysis of non- $\mathrm{CO}_{2}$ driven simulations with the most fundamental method, where the basic assumptions can be checked easily.

Technically, we use the 24 year equilibrium phase of the EMAC experiments (Table 1) to extract twice daily data for $\Delta \mathrm{x}_{\mathrm{i}}$. They are used as input to a radiative transfer model (derived from the ECHAM5 model, Klocke 2011; Klocke et al. 2013) that is fully consistent with the radiation parameterisation used in the EMAC simulations in Table 1 (Dietmüller et al. 2014). Correlations between individual feedbacks can be reduced by combining two variants of the PRP method: the "forward" and the "backward" PRP calculation (Colman and McAvaney 1997; Aires and Rossow 2003; Klocke et al. 2013; Geoffroy et al. 2014). In the forward (fw) case, all parameters except the key parameter $x_{i}^{\prime}$ are taken from the reference simulation to calculate the radiative flux change $\Delta_{i} R^{(f w)}$ :

$\Delta_{i} R^{(f w)}=R\left(x_{i}^{\prime}, x_{j}\right)-R\left(x_{i}, x_{j}\right)$

The climate variables of the climate change simulation are denoted by a prime to distinguish them from the variables of the reference simulation. In the backward (bw) case, all parameters except for the key parameter $x_{i}$ are taken from the climate change simulation to calculate the radiative flux change $\Delta_{i} R^{(b w)}$ :

$\Delta_{i} R^{(b w)}=-\left(R\left(x_{i}, x_{j}^{\prime}\right)-R\left(x_{i}^{\prime}, x_{j}^{\prime}\right)\right)$

The actual feedback is then simply determined as the mean of fw and bw PRP calculations, i.e.:

$\Delta_{i} R=0.5 \cdot\left\{\Delta_{i} R^{(f w)}+\Delta_{i} R^{(b w)}\right\}$

As the closure of the feedback balance is crucial for our purposes, we will pay extra attention to the effect of this calculation method to the size of RES (Eq. 4).

Finally, the feedback parameters are obtained as $\alpha_{i}=\Delta_{i} R / \Delta T_{S}$. We emphasize, however, that some feedbacks like the cloud and the stratospheric temperature feedback may include components that are actually not linked to $\Delta \mathrm{T}_{\mathrm{S}}$.

\section{Results}

\subsection{Feedback analysis of $\mathrm{CO}_{2}$ increase simulations}

As an example for all $\mathrm{CO}_{2}$ increase simulations $(1.2 \times \mathrm{CO} 2$, $2 \times \mathrm{CO} 2,4 \times \mathrm{CO} 2$ ), Fig. 2 shows the global distribution of the feedback parameters for the $2 \times \mathrm{CO} 2$ simulation. The patterns for the other $\mathrm{CO}_{2}$ increase simulations are very similar, but $2 \times \mathrm{CO} 2$ results are best compared with the numerous previous studies available from other climate models (see Bony et al. 2006; Randall et al. 2007, and references therein). Results are presented as the mean of fw and bw PRP calculations (Eq. 7). Positive values indicate an increased downward radiative flux at TOA and thus a positive radiative feedback that supports the warming effect of the $\mathrm{CO}_{2}$ doubling.

The temperature feedback is split up into the Planck, the lapse rate and the stratospheric temperature feedback. The Planck feedback $\alpha_{\text {pla }}$ describes the flux changes due to the surface temperature change which is assumed to be constant throughout the whole troposphere. The geographical distribution of $\alpha_{\text {pla }}$ closely follows the pattern of the surface temperature response. The global mean is $-3.11 \mathrm{Wm}^{-2} \mathrm{~K}^{-1}$ with a $95 \%$ confidence interval of $0.01 \mathrm{Wm}^{-2} \mathrm{~K}^{-1}$ (derived from the interannual standard deviation). The Planck feedback is the largest negative contribution to the total feedback that balances the radiative forcing. Soden and Held (2006) report Planck feedbacks for 14 different climate models, from which we determine a multi-model mean and inter-model standard deviation of $(-3.21 \pm 0.04) \mathrm{Wm}^{-2} \mathrm{~K}^{-1}$. The slightly smaller Planck feedback yielded here is most 
Planck

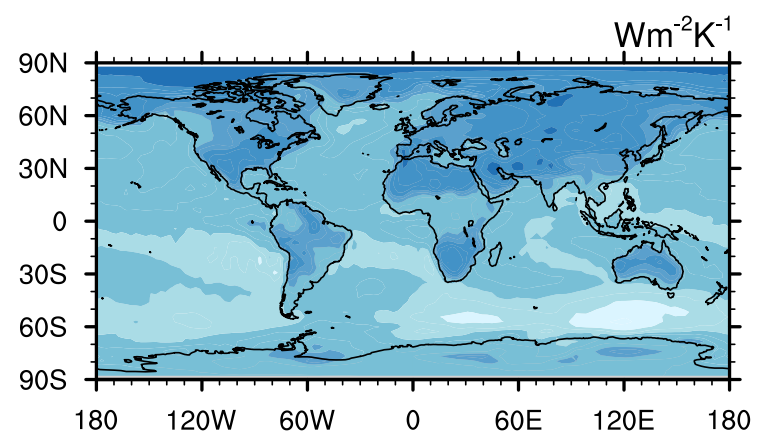

Stratospheric Temperature

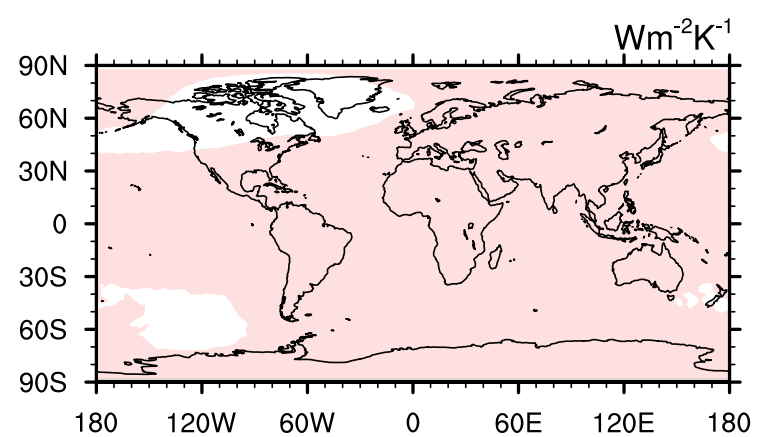

Albedo

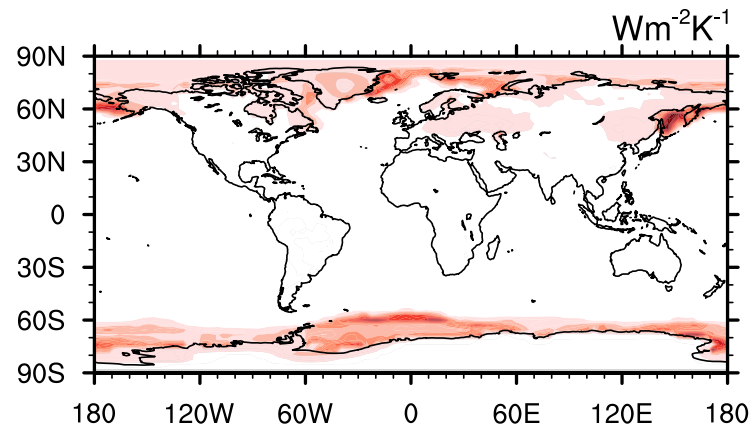

\section{Lapse rate}

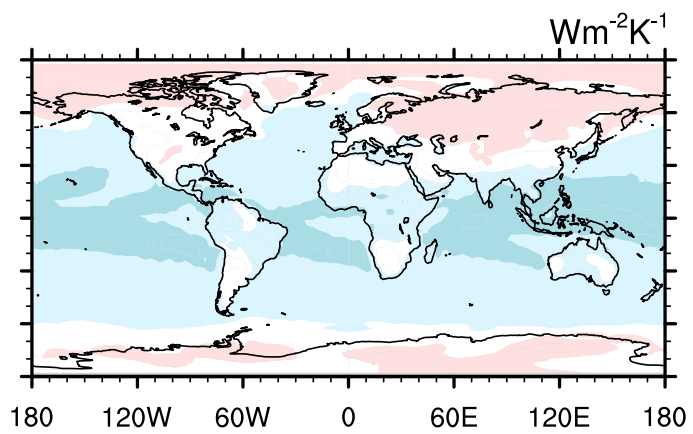

Water vapour

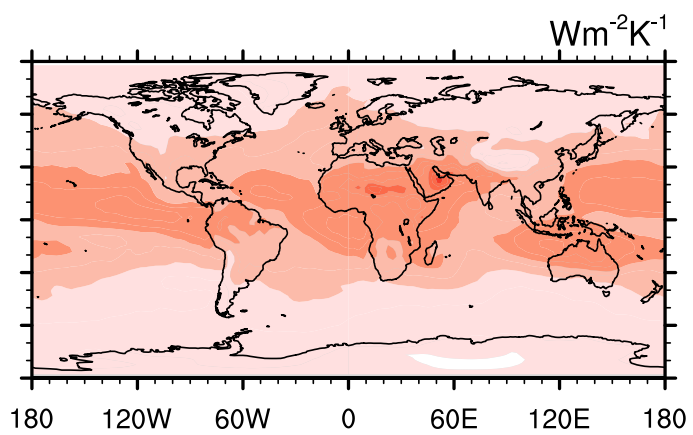

Cloud

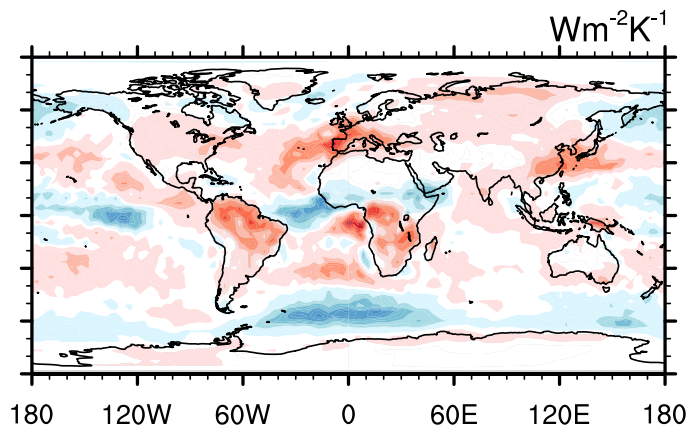

$\begin{array}{llll}2 & 4 & 6 & 8\end{array}$

Fig. 2 Global distribution of Planck, lapse rate, stratospheric temperature, water vapour, albedo and cloud feedback parameters of the $2 \times \mathrm{CO} 2$ simulation at TOA for the combined ( $\mathrm{fw}+\mathrm{bw}$ ) PRP calculation. Units are $\mathrm{Wm}^{-2} \mathrm{~K}^{-1}$. Positive values denote an increase in downward radiation

likely caused by a slight difference in the definition of the tropopause.

The global distribution of the lapse rate feedback $\alpha_{\mathrm{LR}}$ is characterised by positive values at high latitudes and negative values at low latitudes. Doubling of $\mathrm{CO}_{2}$ decreases the lapse rate in the tropics and increases it near the poles. This causes a more (less) effective longwave cooling to space at low (high) latitudes. The global average is negative and has a value of $(-0.86 \pm 0.04) \mathrm{Wm}^{-2} \mathrm{~K}^{-1}$, which is within the multi-model mean of $(-0.84 \pm 0.26) \mathrm{Wm}^{-2} \mathrm{~K}^{-1}$ reported by Bony et al. (2006).
The stratospheric temperature feedback $\alpha_{\text {str }}$ shows a very homogeneous geographical distribution. Enhanced $\mathrm{CO}_{2}$ concentration leads to a stratospheric cooling, reducing the outgoing longwave radiation at TOA. The stratospheric temperature change is caused, on the one hand, by the direct (quasi-instantaneous) $\mathrm{CO}_{2}$ radiative effect and, on the other hand, by changes in dynamic and radiative heating distribution which are controlled by the surface temperature change and thus evolve gradually during the simulation. The global feedback parameter and its corresponding $95 \%$ confidence interval is $(0.56 \pm 0.01) \mathrm{Wm}^{-2} \mathrm{~K}^{-1}$. The 
stratospheric temperature feedback makes a non-negligible contribution to the total temperature feedback and has to be accounted for closing the balance between forcing and feedbacks.

Atmospheric water vapour increases as the troposphere warms, leading to a strong positive feedback $\alpha_{\mathrm{q}}$ of $(2.01 \pm 0.03) \mathrm{Wm}^{-2} \mathrm{~K}^{-1}$. This result is near the upper bound of the multi-model mean of $(1.80 \pm 0.18) \mathrm{Wm}^{-2} \mathrm{~K}^{-1}$ reported by Bony et al. (2006). Potential reasons for this (mainly involving the water vapour reference state in ECHAM5) have been discussed by Ingram (2012). The longwave contribution to the water vapour feedback (82\%) dominates over the shortwave contribution $(18 \%)$. The water vapour feedback can be further split up into changes from tropospheric and stratospheric water vapour. Since we adopt the common convention to consider all feedbacks at TOA, the contribution of tropospheric water vapour is dominating by far $(98 \%)$.

Radiative perturbations due to surface albedo changes only occur at high latitudes, where the albedo reduces in a warmer climate due to a melting of sea ice and snow. Although the albedo feedback $\alpha_{\mathrm{A}}$ can locally reach values up to $9 \mathrm{Wm}^{-2} \mathrm{~K}^{-1}$, its global average of $(0.23 \pm 0.01) \mathrm{Wm}^{-2} \mathrm{~K}^{-1}$ is rather small. This is in good agreement with the multi-model mean of $(0.26 \pm 0.08) \mathrm{Wm}^{-2} \mathrm{~K}^{-1}$ reported by Bony et al. (2006).

The cloud feedback $\alpha_{\mathrm{C}}$ shows locally high values up to $\pm 8 \mathrm{Wm}^{-2} \mathrm{~K}^{-1}$. However, the global average takes a comparatively small value of $(0.29 \pm 0.06) \mathrm{Wm}^{-2} \mathrm{~K}^{-1}$ which just remains within the relatively broad range of the multi-model mean $(0.69 \pm 0.38) \mathrm{Wm}^{-2} \mathrm{~K}^{-1}$ (Bony et al. 2006). The shortwave $\left(-0.13 \pm 0.06 \mathrm{Wm}^{-2} \mathrm{~K}^{-1}\right)$ and longwave $\left(0.42 \pm 0.02 \mathrm{Wm}^{-2} \mathrm{~K}^{-1}\right)$ components of the cloud feedback have opposite signs for the $2 \times \mathrm{CO} 2$ simulation (see Fig. 6), yet the longwave feedback dominates. However, as will be pointed out in the next sub-section, the sign of the shortwave cloud feedback is not constant through the set of $\mathrm{CO}_{2}$ increase simulations.

\subsection{Forcing-feedback-balance at TOA}

For explaining climate sensitivity variations by feedback analysis, a crucial requirement is that the sum of the feedbacks exactly balances the radiative forcing ( $\alpha=\sum_{i} \alpha_{i}=R F / \Delta T_{S}$, Eqs. 1, 3, 4). In Fig. 3 we show this balance by comparing the absolute value of the instantaneous radiative forcing $\mathrm{RF}_{\text {inst }}$ (normalized by $\Delta \mathrm{T}_{\mathrm{s}}$ ) with the total feedback $\alpha$ and the feedbacks' sum $\sum \alpha_{i}$ for the fw, the bw and the combined (fw+bw) PRP calculations for $2 \times \mathrm{CO} 2$. To calculate the total feedback $\alpha$ for the fw PRP calculation, all feedback relevant variables of the reference simulation (but not the $\mathrm{CO}_{2}$ increase which causes the forcing) are replaced by the variables of the climate change simulation and vice versa for the bw PRP calculation. All feedbacks are calculated by the instantaneous flux change at TOA. Thus, to consistently balance forcing and feedback, fw PRP

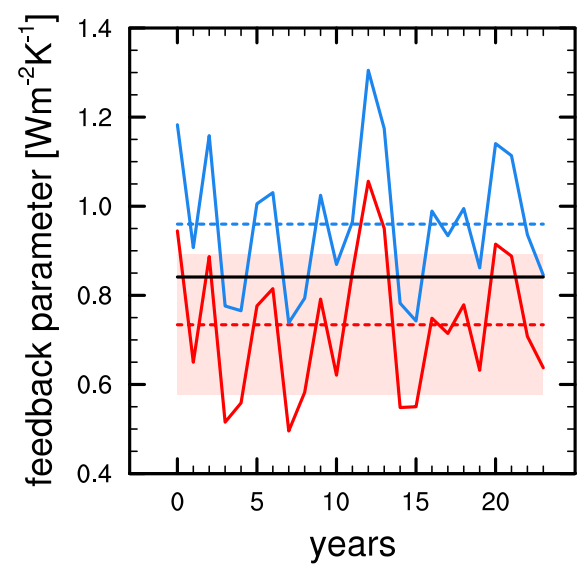

bw PRP

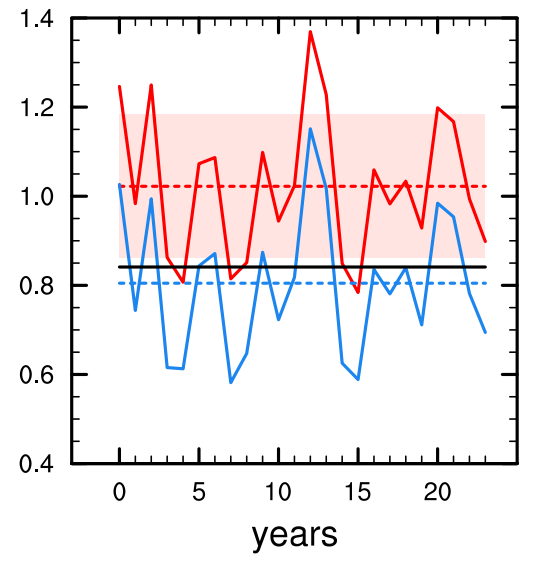

radiative forcing

total feedback $(\mathrm{fw}+\mathrm{bw}) \mathrm{PRP}$

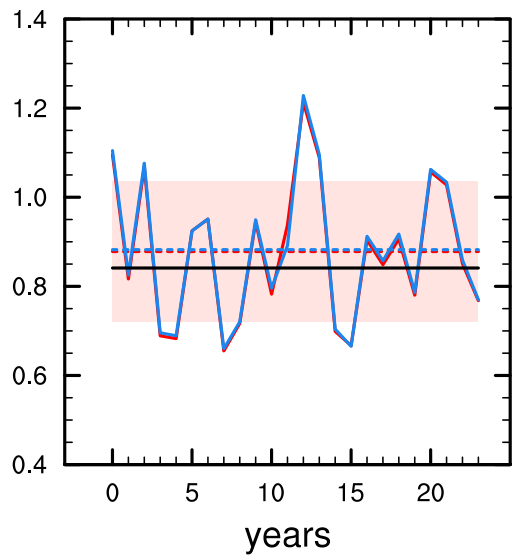

Fig. 3 Additivity of feedbacks at TOA. The sum of feedbacks $\sum \alpha_{i}$ (red lines) and the total feedback $\alpha$ (blue lines) in $\mathrm{Wm}^{-2} \mathrm{~K}^{-1}$ for the $2 \times \mathrm{CO} 2$ simulation are compared. The fw, bw and combined $(\mathrm{fw}+\mathrm{bw})$ PRP calculations are presented for 24 years. The dashed lines indicate the multi-year mean values. The red shaded area represents the standard deviation of the feedbacks' sum. Black solid lines indicate the absolute value of the instantaneous radiative forcing $\mathrm{RF}_{\text {inst }}$ (normalized by $\Delta \mathrm{T}_{\mathrm{s}}$ ) in $\mathrm{Wm}^{-2} \mathrm{~K}^{-1}$ at TOA 
it is necessary to also use the $\mathrm{RF}_{\text {inst }}$ at TOA (rather than $\mathrm{RF}_{\text {adj }}$ from Table 1). The $\mathrm{RF}_{\text {inst, }}$, the respective climate sensitivity $\lambda_{\text {inst }}$ and the $\mathrm{RF}_{\text {inst }}$ normalized by $\Delta \mathrm{T}_{\mathrm{s}}$ for all simulations are listed in Table 2 . The values for $\mathrm{RF}_{\text {inst }}$ have been yielded by a two-sided calculation (mean of the radiative effects by adding $\mathrm{CO}_{2}$ to REF conditions and removing $\mathrm{CO}_{2}$ from perturbed conditions), which appears to be most consistent with the combined ( $f w+b w)$ PRP calculations of the feedbacks. However, it must be noted that this calculation of $\mathrm{RF}_{\text {inst }}$ is not consistent with the common definition of $\mathrm{RF}_{\text {inst }}$. According to the common definition, $\mathrm{RF}_{\text {inst }}$ is calculated by just adding a $\mathrm{CO}_{2}$ increment to the reference concentration (i.e. 368 ppmv) under REF conditions, i.e. by doing a 'forward' calculation. The results of forward calculations of $\mathrm{RF}_{\text {inst }}$ are also included (in italics) to Table 2.

For the fw PRP calculation, Fig. 3 shows that neither the feedbacks' sum nor the total feedback equals the $\mathrm{RF}_{\text {inst }}$ (normalized by $\Delta \mathrm{T}_{\mathrm{s}}$ ) with the required accuracy. Nor does the total feedback agree to the feedbacks' sum. This indicates that the individual feedbacks are not completely additive. For the bw PRP calculation, the total feedback almost equals the radiative forcing (normalized by $\Delta \mathrm{T}_{\mathrm{s}}$ ), but the sum of feedbacks deviates substantially. Only the combined $(\mathrm{fw}+\mathrm{bw}$ ) PRP calculation shows an almost perfect agreement of radiative forcing (normalized by $\Delta \mathrm{T}_{\mathrm{s}}$ ), feedbacks' sum and total feedback. The total feedback and the feedbacks' sum deviate by less than $0.01 \mathrm{Wm}^{-2} \mathrm{~K}^{-1}$, which may be regarded as negligibly small. The difference between the sum of feedbacks and the radiative forcing is only $0.04 \mathrm{Wm}^{-2} \mathrm{~K}^{-1}$ which corresponds to about $5 \%$ of the forcing. This is distinctly smaller than in previous feedback studies (Shell et al. 2008; Klocke et al. 2013). Thus, the radiative equilibrium is fully restored within the statistical uncertainty limits. Moreover, tests for selected pairs or triples of individual feedbacks (not shown) have confirmed that the additivity of individual feedbacks is only guaranteed when the combined $(\mathrm{fw}+\mathrm{bw})$ calculation method is used. Consequently, only the combined ( $\mathrm{fw}+\mathrm{bw}$ ) PRP calculation meets the conceptual requirements of the PRP analysis (see also Klocke et al. 2013).

If we apply the common definition of $\mathrm{RF}_{\text {inst }}$ (italic numbers Table 1) to our considerations above, we reach the same conclusions as for the $\mathrm{RF}_{\text {inst }}$ yielded by the (fw + bw) calculation for $1.2 \times \mathrm{CO} 2$ and $2 \times \mathrm{CO} 2$. However, for the $4 \times \mathrm{CO} 2$ simulation the agreement between the $\mathrm{RF}_{\text {inst }}$ (normalized by $\Delta \mathrm{T}_{\mathrm{s}}$ ) and the feedbacks' sum $\sum \alpha_{i}$ vanishes. We suspect that a correlation between the $\mathrm{CO}_{2}$ radiative impact and the temperature change is responsible for this effect.

Moreover, the differences of fw and bw PRP calculations are clearly visible in the radiative flux changes. For the three $\mathrm{CO}_{2}$ increase simulations, Fig. 4 shows the flux changes which corresponds to the feedbacks. The differences of flux changes calculated with the fw and bw PRP method $\left(\Delta_{\mathrm{i}} \mathrm{R}^{(\mathrm{fw})}, \Delta_{\mathrm{i}} \mathrm{R}^{(\mathrm{bw})}\right)$ grow with increasing forcing for $\alpha_{\text {pla }}, \alpha_{\text {str }}$ and $\alpha_{A}$. Interestingly, for $\alpha_{\text {lap }}, \alpha_{\mathrm{q}}$ and $\alpha_{C}$, the difference stays constant with increasing forcing. Figure 4 demonstrates that even the sign of $\alpha_{\text {lap }}, \alpha_{q}$ and $\alpha_{C}$ may differ between the fw and bw PRP calculation for $1.2 \times \mathrm{CO} 2$. If feedback parameters $\alpha_{\mathrm{i}}$ (rather than flux changes $\Delta_{\mathrm{i}} \mathrm{R}$ ) are considered, the spread spanned by fw and bw calculated results becomes even wider with decreasing forcing for $\alpha_{\text {lap }}, \alpha_{\mathrm{q}}$ and $\alpha_{\mathrm{C}}$. Hence, the correlations between the individual feedbacks, which are responsible for the differences of $\mathrm{fw}$ and bw PRP calculations, appear not to decrease with decreasing forcing.
Table 2 Key parameters of the feedback analysis for the equilibrium climate change simulations

\begin{tabular}{lllll}
\hline Simulation & $\mathrm{RF}_{\text {inst }}\left[\mathrm{Wm}^{-2}\right]$ & $\lambda_{\text {inst }}\left[\mathrm{KW}^{-1} \mathrm{~m}^{2}\right]$ & $\begin{array}{l}\mathrm{RF}_{\text {inst }}(\text { normalized by } \\
\left.\Delta \mathrm{T}_{\mathrm{s}}\right)\left[\mathrm{Wm}^{-2} \mathrm{~K}^{-1}\right]\end{array}$ & $\sum \alpha_{\mathrm{i}}\left[\mathrm{Wm}^{-2} \mathrm{~K}^{-1}\right]$ \\
\hline $\mathrm{REF}$ & - & - & - & - \\
$\mathrm{NOX}+\mathrm{CO}$ & $1.01 \pm 0.000$ & $0.74 \pm 0.05$ & $1.41 \pm 0.12$ & $-1.33 \pm 0.20$ \\
& $1.01 \pm 0.000$ & $0.74 \pm 0.05$ & $1.40 \pm 0.12$ & $-0.77 \pm 0.22$ \\
$1.2 \times \mathrm{CO} 2$ & $0.63 \pm 0.000$ & $1.12 \pm 0.07$ & $0.92 \pm 0.06$ & $-0.88 \pm 0.07$ \\
& $0.61 \pm 0.001$ & $1.15 \pm 0.08$ & $0.90 \pm 0.06$ & \\
$2 \times \mathrm{CO} 2$ & $2.54 \pm 0.002$ & $1.10 \pm 0.02$ & $0.92 \pm 0.02$ & $-0.73 \pm 0.03$ \\
& $2.34 \pm 0.003$ & $1.19 \pm 0.02$ & $0.84 \pm 0.02$ & \\
$4 \times \mathrm{CO} 2$ & $5.70 \pm 0.004$ & $1.37 \pm 0.02$ & $0.73 \pm 0.01$ & \\
& $4.81 \pm 0.007$ & $1.63 \pm 0.02$ & $0.62 \pm 0.01$ & \\
\hline
\end{tabular}

The instantaneous radiative forcing $\mathrm{RF}_{\text {inst }}$, the corresponding climate sensitivity $\lambda_{\text {inst }}, \mathrm{RF}_{\text {inst }}$ (normalized by $\Delta \mathrm{T}_{\mathrm{s}}$ ) and the feedbacks' sum $\sum \alpha_{\mathrm{i}}$ as well as their corresponding $95 \%$ confidence interval are listed. The values of $\mathrm{RF}_{\text {inst }}, \lambda_{\text {inst }}$ and $\mathrm{RF}_{\text {inst }}$ (normalized by $\Delta \mathrm{T}_{\mathrm{s}}$ ) are calculated by a combined ( $\mathrm{fw}+\mathrm{bw}$ ) PRR method, while the italic numbers refer to the $\mathrm{RF}_{\text {inst }}$ values according to the fw PRP calculation (see text). All values are calculated year by year and then averaged 

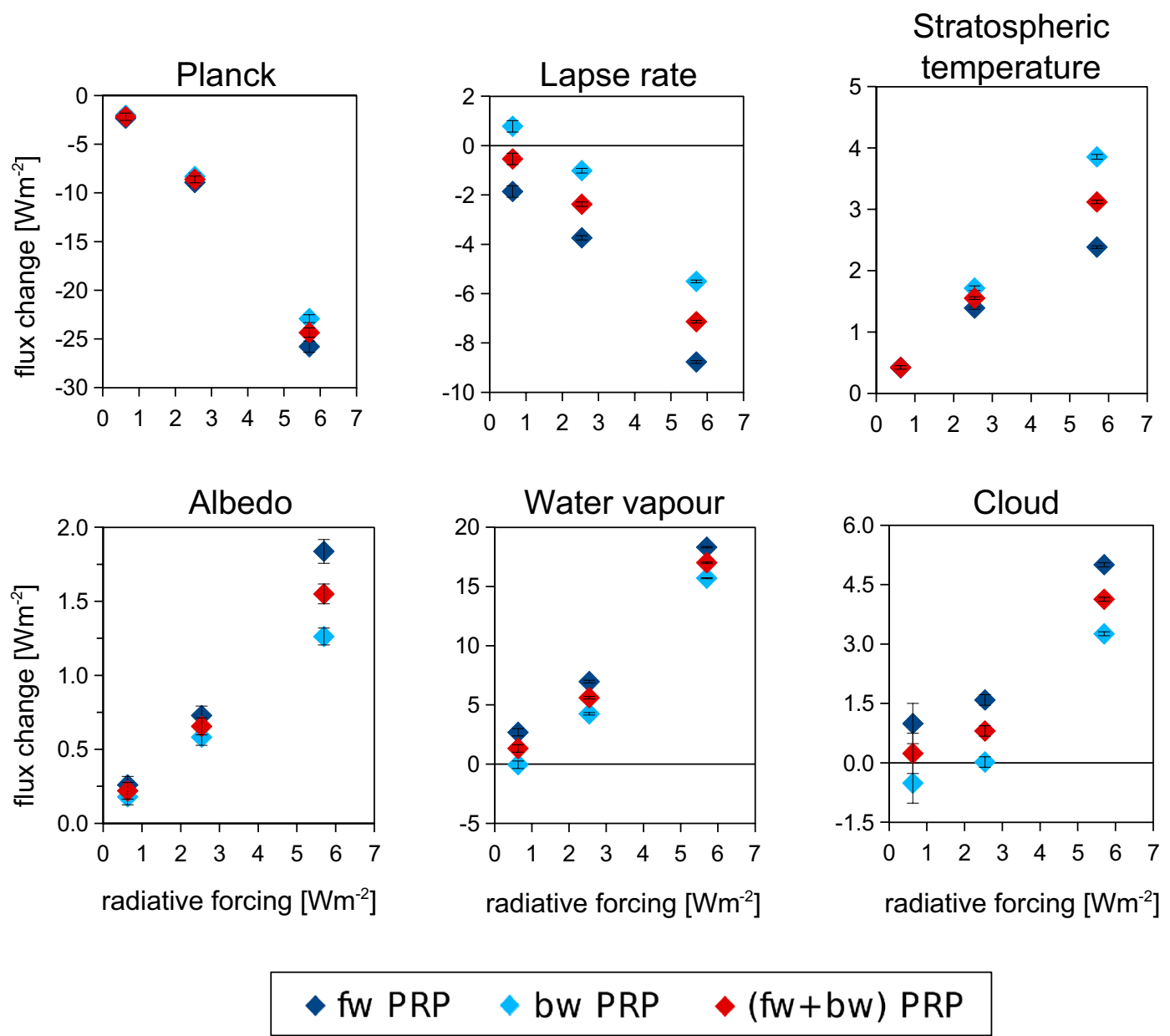

Fig. 4 Comparison of flux changes $\left(\Delta_{\mathrm{i}} \mathrm{R}^{(\mathrm{fw})}, \Delta_{\mathrm{i}} \mathrm{R}^{(\mathrm{bw})}, \Delta_{\mathrm{i}} \mathrm{R}\right)$ of the forward (fw), backward (bw) and combined (fw + bw) PRP method for the $1.2 \times \mathrm{CO} 2\left(\mathrm{RF}_{\mathrm{inst}}=0.63 \mathrm{Wm}^{-2}\right), 2 \times \mathrm{CO} 2\left(\mathrm{RF}_{\text {inst }}=2.54 \mathrm{Wm}^{-2}\right)$

\subsection{Feedback and climate sensitivity differences for $\mathrm{CO}_{2}$ increase simulations}

The feedback parameters and their $95 \%$ confidence bars derived from the interannual variability for the three $\mathrm{CO}_{2}$ increase simulations $(1.2 \times \mathrm{CO} 2,2 \times \mathrm{CO} 2,4 \times \mathrm{CO} 2)$ are shown in Fig. 5. We first discuss the straightforward balance of feedbacks with $\mathrm{RF}_{\text {inst }}$ at TOA (Fig. 5a; Table 2), and then address the issue of stratospheric temperature adjustment (Fig. 5b; Table 1).

The Planck feedback $\alpha_{\text {pla }}$ stays rather constant as the radiative forcing increases with the perturbation strength. This feature of $\mathrm{CO}_{2}$ increase simulations has been reported previously, e.g. by Colman and McAvaney (2009). Other feedbacks show gradual changes in magnitude, either decreasing $\left(\alpha_{\mathrm{LR}}, \alpha_{\mathrm{str}}, \alpha_{\mathrm{A}}\right)$ or increasing $\left(\alpha_{\mathrm{q}}\right)$ with increasing forcing. For $\alpha_{\mathrm{str}}, \alpha_{\mathrm{A}}$ and $\alpha_{\mathrm{q}}$, the $95 \%$-confidence intervals do not overlap for the three simulations. This suggests significant trends from $1.2 \times \mathrm{CO} 2$ to and $4 \times \mathrm{CO} 2\left(\mathrm{RF}_{\mathrm{inst}}=5.70 \mathrm{Wm}^{-2}\right)$ simulations. The uncertainty bars reflect the interannual variability for each simulation

$4 \times \mathrm{CO} 2$. Some of these trends can be easily explained. For example, the $35 \%$ decrease of $\alpha_{\mathrm{A}}$ from $1.2 \times \mathrm{CO} 2$ to $4 \times \mathrm{CO} 2$ can be described as follows: in a warmer climate, less snow and ice is available to melt if the warming continues. In the troposphere, $\alpha_{\mathrm{q}}$ is largely controlled by the carrying capacity of warmer air under the constraint of constant relative humidity. Its significant increase from $(1.88 \pm 0.09) \mathrm{Wm}^{-2} \mathrm{~K}^{-1}$ to $(2.18 \pm 0.02) \mathrm{Wm}^{-2} \mathrm{~K}^{-1}$ is in good agreement with respective results reported by Colman and McAvaney (2009). The trend in $\alpha_{q}$ can be explained by an enhanced specific humidity in the upper tropical troposphere. This process is connected to a tropopause rise as the tropical sea surface temperatures increases (Meraner et al. 2013; Dietmüller et al. 2014). Note that, in contrast to the results of Colman and McAvaney (2009), the combined water vapour and lapse rate feedback $\alpha_{\mathrm{q}+\mathrm{LR}}$ also increases with increasing forcing for our simulations. Convection closely links these two feedbacks together and thus, both feedbacks partly 


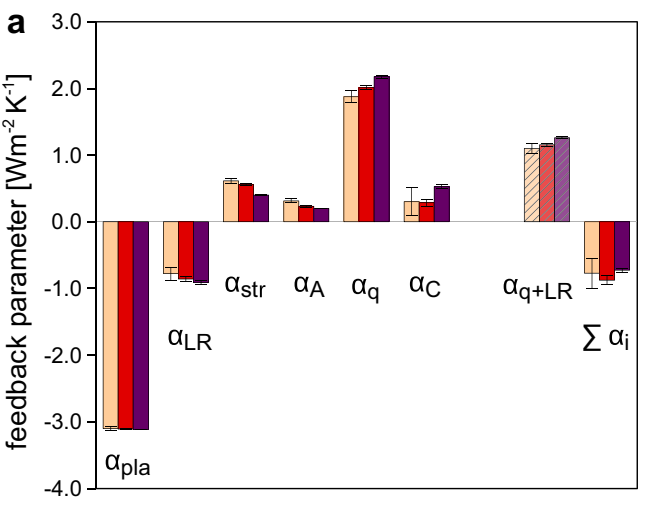

Fig. 5 Comparison between the $1.2 \times \mathrm{CO} 2,2 \times \mathrm{CO} 2$ and $4 \times \mathrm{CO} 2$ simulations for the Planck $\alpha_{\text {pla }}$, lapse rate $\alpha_{\mathrm{LR}}$, stratospheric temperature $\alpha_{\text {str }}$, albedo $\alpha_{\mathrm{A}}$, water vapour $\alpha_{\mathrm{q}}$ and cloud $\alpha_{\mathrm{C}}$ feedbacks (a) based on instantaneous feedback calculations (b) based on the stratosphere adjusted concept. Hatched columns indicate the combined water

compensate each other (Allan et al. 2002; Soden and Held 2006; Sherwood et al. 2010).

The $95 \%$ confidence interval of the cloud feedback is clearly the largest. This prevents the identification of a clear trend for $\alpha_{C}$. Yet $\alpha_{C}$ is found to be significantly enhanced in $4 \times \mathrm{CO} 2$ compared to both $2 \times \mathrm{CO} 2$ and $1.2 \times \mathrm{CO} 2$ (on a 90\% significance level). As shown in Fig. 6, this is mainly induced by a change of sign in the shortwave component of $\alpha_{C}$. The feature is consistent with a weakening negative cloud phase feedback as the forcings increases (Mitchell et al. 1989; McCoy et al. 2014; Tan et al. 2016). It is noteworthy that this effect has been indicated for $\mathrm{CO}_{2}$-driven (Tan et al. 2016) and non- $\mathrm{CO}_{2}$ driven (Shine et al. 2012) climate change simulations. The underlying regional processes cannot be studied further here as the statistical noise is too high.

The feedbacks' sum of the $1.2 \times \mathrm{CO} 2$ simulation shows such a high statistical uncertainty (Table 2; Fig. 5a, b) that a significant difference from the $2 \times \mathrm{CO} 2$ and $4 \times \mathrm{CO} 2$ simulations cannot be established. Hence, the feedback analysis for the $1.2 \times \mathrm{CO} 2$ simulation is not suitable to explain the differences in climate sensitivity. This is consistent as also the climate sensitivities of $1.2 \times \mathrm{CO} 2$ and $2 \times \mathrm{CO} 2$ do not significantly differ for $\lambda_{\text {inst }}$ (and neither for $\lambda_{\text {adj }}$ ).

For $4 \times \mathrm{CO} 2, \lambda_{\text {inst }}$ increases by $26 \%$ relative to $2 \times \mathrm{CO} 2$ (Table 2). Thus, $\mathrm{RF}_{\text {inst }}$ (normalized by $\Delta \mathrm{T}_{\mathrm{s}}$ ) drops by about $0.19 \mathrm{Wm}^{-2} \mathrm{~K}^{-1}$. The absolute value of the feedbacks' sum $\sum \alpha_{i}$ also decreases by $0.15 \mathrm{Wm}^{-2} \mathrm{~K}^{-1}$. These changes are significant and allow an attempt to look for physical causes by analysing the individual feedbacks.

From $2 \times \mathrm{CO} 2$ to $4 \times \mathrm{CO} 2, \alpha_{\mathrm{A}}$ weakens slightly by $0.03 \mathrm{Wm}^{-2} \mathrm{~K}^{-1}$, while $\alpha_{\text {str }}$ drops substantially by about $0.16 \mathrm{Wm}^{-2} \mathrm{~K}^{-1}$. These effects are dominated by an increase of $\alpha_{\mathrm{q}+\mathrm{LR}}\left(0.11 \mathrm{Wm}^{-2} \mathrm{~K}^{-1}\right)$ and $\alpha_{\mathrm{C}}\left(0.24 \mathrm{Wm}^{-2} \mathrm{~K}^{-1}\right)$. Thus,

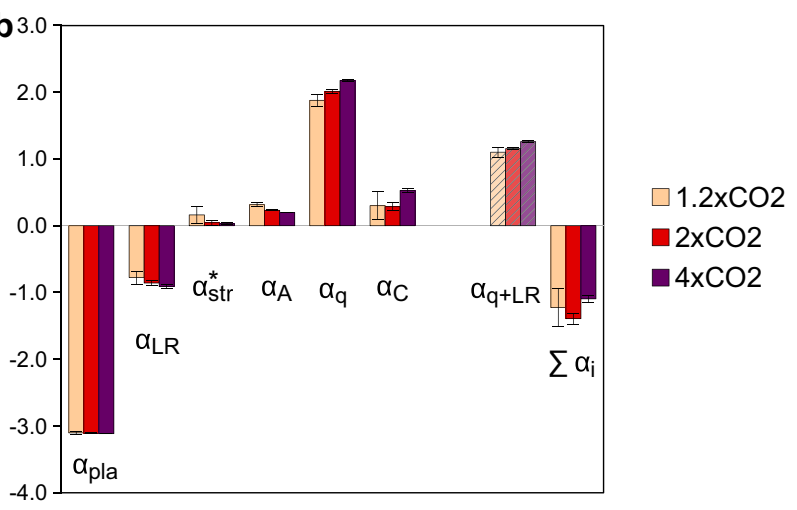

vapour and lapse rate feedback $\alpha_{\mathrm{q}+\mathrm{LR}}$. The feedbacks' sum $\sum \alpha_{\mathrm{i}}$ is shown in the right columns. Uncertainty bars for each column indicate the $95 \%$ confidence interval of the multi-year mean for each feedback parameter. All feedbacks are displayed for the combined (fw + bw) PRP method

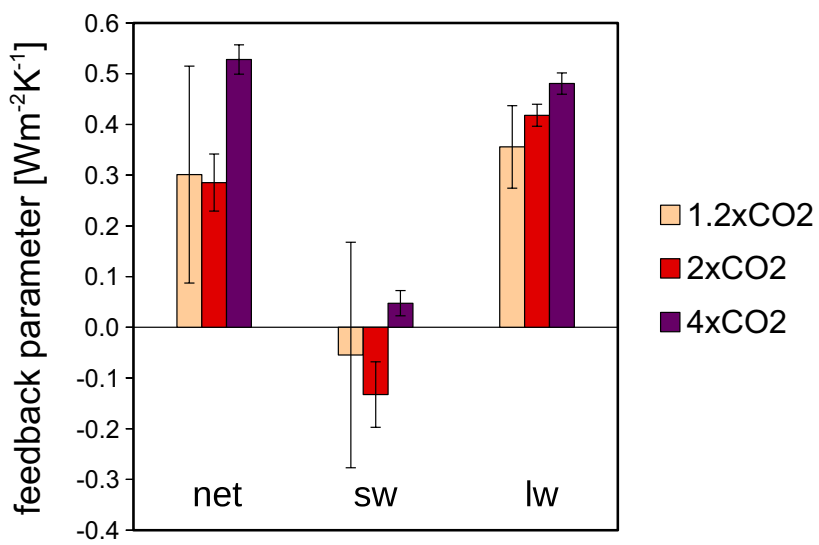

Fig. 6 Comparison between the $1.2 \times \mathrm{CO} 2,2 \times \mathrm{CO} 2$ and $4 \times \mathrm{CO} 2$ simulations for the net, shortwave (sw) and longwave (lw) cloud feedbacks. Uncertainty bars for each column indicate the $95 \%$ confidence interval of the multi-year mean. Feedbacks are displayed for the combined $(\mathrm{fw}+\mathrm{bw})$ PRP method

the strengthening of two positive feedbacks $\left(\alpha_{\mathrm{q}}, \alpha_{\mathrm{C}}\right)$ drives the feedbacks' sum to a significantly less negative value for $4 \times \mathrm{CO} 2$ (Fig. 5a). This explains the instantaneous climate sensitivity $\lambda_{\text {inst }}$ increase from $2 \times \mathrm{CO} 2$ to $4 \times \mathrm{CO} 2$ (Table 2 ).

We may explain the variations in stratosphere adjusted climate sensitivity $\lambda_{\text {adj }}$ (Table 1 ) in an analogous way as for $\lambda_{\text {inst }}$. We derive the "stratosphere adjustment part" of $\alpha_{\text {str }}$ from $\lambda_{\text {adj }}$ and $\lambda_{\text {inst }}$ as

$\delta \alpha_{s t r}=\frac{R F_{a d j}-R F_{\text {inst }}}{\Delta T_{S}}=\frac{1}{\lambda_{a d j}}-\frac{1}{\lambda_{\text {inst }}}$

Thus, by subtracting the stratosphere adjustment part of $\alpha_{\text {str }}$, we obtain the "pure" stratospheric temperature 
feedback $\alpha^{*}{ }_{\text {str }}=\alpha_{\text {str }}-\delta \alpha_{\text {str. }}$. It describes the radiative flux changes which are controlled by changes in surface temperature. Figure $5 \mathrm{~b}$ shows the new feedback balance in the stratosphere adjustment framework. $\alpha^{*}{ }_{\text {str }}$ almost vanishes and thus does not significantly contribute to the feedbacks' sum anymore. Hence, we can conclude that $\alpha^{*}$ str has little influence on $\lambda_{\text {adj }}$. Variations in $\lambda_{\text {adj }}$ for $\mathrm{CO}_{2}$ increase simulations can be explained by $\alpha_{\mathrm{A}}, \alpha_{\mathrm{C}}$ and $\alpha_{\mathrm{q}+\mathrm{LR}}$.

Overall consideration of the three $\mathrm{CO}_{2}$ increase simulations suggests that it is possible to identify crucial feedbacks which are responsible for a change in climate sensitivity. The constraint is that the forcing must not get so small that statistical uncertainties of individual feedbacks and of the feedbacks' sum exceed a crucial level. This level depends on the magnitude of the climate sensitivity differences to be explained. For the series of $\mathrm{CO}_{2}$ simulations with an equilibrium phase of 24 years, $1 \mathrm{Wm}^{-2}$ forcing is obviously not large enough.

\subsection{Feedback and climate sensitivity differences for NOX + CO simulation}

As shown in the previous section, feedback parameters may depend on the magnitude of forcing. We now compare the feedback parameters of different forcing types. Since NOX $+\mathrm{CO}$ and $1.2 \times \mathrm{CO} 2$ simulations have about the same magnitude of $\mathrm{RF}_{\mathrm{adj}}$, a comparison of their feedbacks (Fig. 7) is sensible. The climate sensitivities $\lambda_{\text {adj }}$ of both simulations (Table 1) are distinguishable on a $95 \%$ significance level. This justifies an attempt to explain the efficacy reduction of $\mathrm{NOX}+\mathrm{CO}$ by a feedback analysis.

The Planck feedback $\alpha_{\text {pla }}$ in $\mathrm{NOX}+\mathrm{CO}$ is $(-3.16 \pm 0.02) \quad \mathrm{Wm}^{-2} \mathrm{~K}^{-1}$, which makes a small but statistically significant difference to $\alpha_{\text {pla }}$ of $(-3.10 \pm 0.02) \mathrm{Wm}^{-2} \mathrm{~K}^{-1}$ in $1.2 \times \mathrm{CO} 2$. Changes of $\alpha_{\mathrm{q}}$ and $\alpha_{\mathrm{LR}}$ are greater. The magnitude of both feedbacks is larger in $1.2 \times \mathrm{CO} 2$ than in NOX $+\mathrm{CO}: \alpha_{\mathrm{q}}$ increases from
$(1.88 \pm 0.09)$ to $(2.32 \pm 0.07) \mathrm{Wm}^{-2} \mathrm{~K}^{-1}$ and $\alpha_{\mathrm{LR}}$ decreases from $(-0.78 \pm 0.10)$ to $(-1.18 \pm 0.10) \mathrm{Wm}^{-2} \mathrm{~K}^{-1}$. However, the combined feedbacks $\alpha_{\mathrm{q}+\mathrm{LR}}$ stays almost constant. As mentioned above, $\alpha_{L R}$ and $\alpha_{q}$ are closely related to the same physical process (convection). Consequently, we can conclude that a change in the convection does not significantly influence $\alpha_{\mathrm{q}+\mathrm{LR}}$ and thus the efficacy. The difference of $\alpha_{\mathrm{str}}$ is substantial. $\alpha_{\text {str }}$ is $\left(0.36 \pm 0.03 \mathrm{Wm}^{-2} \mathrm{~K}^{-1}\right)$ for $\mathrm{NOX}+\mathrm{CO}$ and $\left(0.61 \pm 0.04 \mathrm{Wm}^{-2} \mathrm{~K}^{-1}\right)$ for $1.2 \times \mathrm{CO} 2 . \alpha_{\mathrm{A}}$ is slightly smaller in $1.2 \times \mathrm{CO} 2\left(0.31 \pm 0.03 \mathrm{Wm}^{-2} \mathrm{~K}^{-1}\right)$ than in $\mathrm{NOX}+\mathrm{CO} \quad\left(0.25 \pm 0.04 \mathrm{Wm}^{-2} \mathrm{~K}^{-1}\right) . \alpha_{\mathrm{C}}$ changes more strongly, from $(0.30 \pm 0.21) \mathrm{Wm}^{-2} \mathrm{~K}^{-1}$ in $1.2 \times \mathrm{CO} 2$ to $(0.08 \pm 0.20) \mathrm{Wm}^{-2} \mathrm{~K}^{-1}$ in NOX $+\mathrm{CO}$. However, the yearto-year variability of $\alpha_{C}$ is so large that $\alpha_{C}$ of $\mathrm{NOX}+\mathrm{CO}$ and $1.2 \times \mathrm{CO} 2$ cannot be distinguished on a $95 \%$ significance level. We can conclude that $\alpha_{\text {pla }}, \alpha_{\mathrm{A}}$ and $\alpha_{\text {str }}$ causes the difference in the feedbacks' sum and thus in the climate sensitivity $\lambda_{\text {inst }}$. Moreover, we assume that $\alpha_{C}$ also contributes to the variations in the feedbacks' sum and in $\lambda_{\text {inst }}$, but the statistical significance of $\alpha_{C}$ is too low to make a conclusive statement.

Figure $7 \mathrm{~b}$ shows the feedback balance for the stratosphere adjustment concept. As described above, we remove the stratosphere adjustment part from $\alpha_{\text {str }}$ Now, the pure stratospheric temperature feedback $\alpha^{*}{ }_{\text {str }}$ is not distinguishable between $\mathrm{NOX}+\mathrm{CO}$ and $1.2 \times \mathrm{CO} 2$. Moreover, the feedbacks' sum cannot be distinguished on a convincing significance level either. Consequently, it is difficult to relate changes in feedbacks to the significant change in climate sensitivity $\lambda_{\text {adj. }}$.

Summarizing, we can identify the feedbacks which are responsible for changes in the instantaneous climate sensitivity (Fig. 7a). Here, the large decrease of $\alpha_{\text {str }}$ from $1.2 \times \mathrm{CO} 2$ to $\mathrm{NOX}+\mathrm{CO}$ is part of the feedback balance. Thus, the change in $\alpha_{\text {str }}$ is mainly responsible for the significant difference in $\lambda_{\text {inst }}$ between $1.2 \times \mathrm{CO} 2$ and $\mathrm{NOX}+\mathrm{CO}$. Considering the feedback analysis within the stratosphere
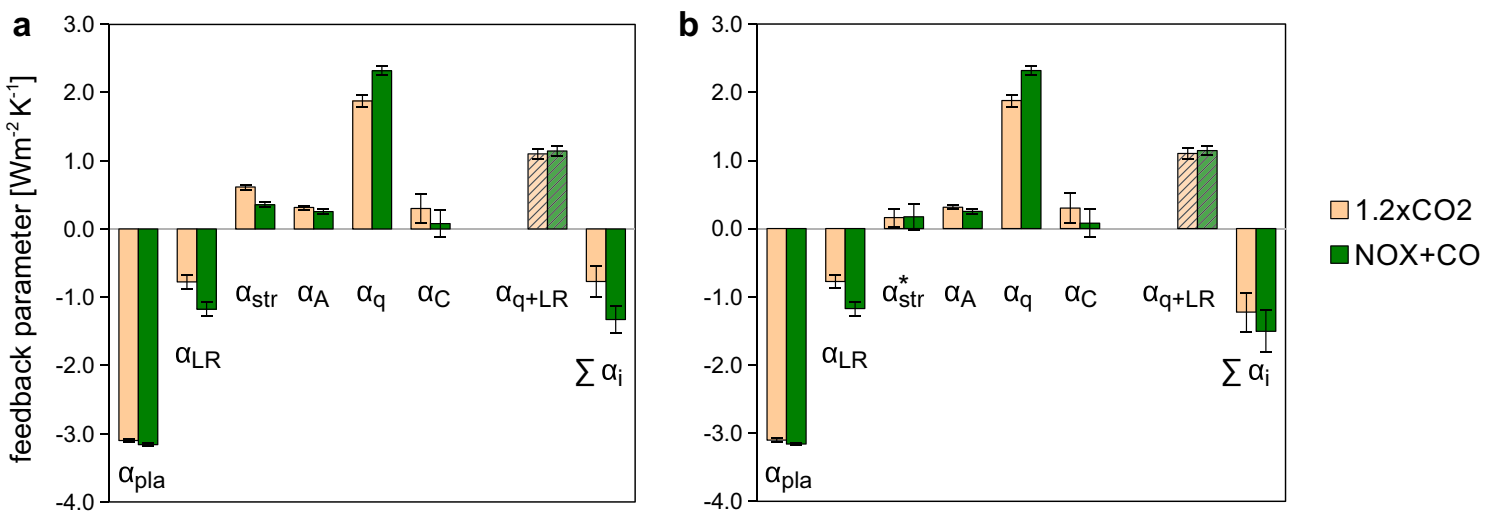

Fig. 7 As Fig. 5, but showing the comparison of the feedback parameters for the $1.2 \times \mathrm{CO} 2$ and the NOX $+\mathrm{CO}$ simulations 
adjustment concept (Fig. 7b), the interpretation is more critical. The stronger negative feedbacks' sum of $\mathrm{NOX}+\mathrm{CO}$ is consistent with the significant reduction of $\lambda_{\text {adj }}$ (Table 1). However, the change of the feedbacks' sum is not statistical significant which does not allow a fully convincing conclusion about the origins of the variations in $\lambda_{\text {adj: }}$

\section{Discussion}

\subsection{Methodical aspects}

By analysing global mean radiative feedbacks, we investigated the potential to identify the physical causes for climate sensitivity and efficacy variations of different radiative forcings. We tested a set of $\mathrm{CO}_{2}$-forced simulations as well as a non- $\mathrm{CO}_{2}$-forced simulation. The latter has a radiative forcing of about $1 \mathrm{Wm}^{-2}$. This is much smaller than the $\mathrm{CO}_{2}$ forcings usually applied when performing a feedback analysis, but still requires considerable scaling of the emissions causing the non- $\mathrm{CO}_{2}$ forcing. The crucial problem when addressing non- $\mathrm{CO}_{2}$ forcings is that they contribute less to the total anthropogenic forcing than realistic $\mathrm{CO}_{2}$ changes. This leads to statistical detection problems, as all relevant parameters (climate sensitivity and radiative feedbacks) emerge less clearly from their internal variability.

The prospects to attribute climate sensitivity and efficacy variations to changes in individual feedback processes can be promising if some methodological rules are followed.

First, it is imperative to apply the PRP method with the combination of fw and bw feedback calculations. This ensures: (1) the additivity of the individual feedbacks and (2) the required radiative balance closure at TOA (Fig. 3). Neither fw nor bw calculation are sufficient in this respect, as reported previously (e.g. Klocke et al. 2013). These two conditions are crucial for attributing climate sensitivity changes to feedback changes and are only fulfilled for the combination of fw and bw PRP method.

Second, a feedback comparison of different forcing types is only possible if the forcings have the same magnitude. The climate sensitivity depends not only on the type but also on the magnitude of forcing. Thus, for forcings with very different magnitude, a feedback analysis to assess efficacy differences may become meaningless.

Third, the scaling factor applied to the non- $\mathrm{CO}_{2}$ forcing (in our case: $\mathrm{O}_{3}$ change due to the $\mathrm{NO}_{\mathrm{x}}$ and $\mathrm{CO}$ surface emissions) has to be considered carefully. On the one hand, this scaling should be as small as possible to limit non-linearities between perturbation and forcing. Test simulations showed that the radiative forcing of the $\mathrm{O}_{3}$ pattern driving $\mathrm{NOX}+\mathrm{CO}$ (Fig. 1) is approximately linear with the scaling factor (Dietmüller 2011). On the other hand, the scaling of the forcing has to be sufficiently large to ensure that surface temperature response and feedback changes can be recognized from its internal variability. Our choice to scale the forcing to $1 \mathrm{Wm}^{-2}$ has turned out to be just sufficient to establish significantly different feedback parameters. However, it becomes already problematic if cloud feedback changes should be interpreted.

\subsection{Interpretation aspects}

Climate sensitivities and efficacies for different forcing types are best compared if the radiative forcing is calculated with stratospheric temperature adjustment and determined at the tropopause (Hansen et al. 2005; Myhre et al. 2013). In contrast, feedback analysis is traditionally carried out using instantaneous radiative flux changes at TOA. These conventions exist for good reasons, but have hindered the straightforward interpretation of the forcingfeedback balance in Sect. 3 .

To address this problem, we introduce a new feedback parameter: the stratospheric temperature feedback $\alpha_{\text {str }}$ It describes the instantaneous radiative flux changes at TOA due to stratospheric temperature change caused by a forcing. $\alpha_{\text {str }}$ consistently explains variations in the instantaneous climate sensitivity $\lambda_{\text {inst }}$. However, a large part of $\alpha_{\text {str }}$ is provided by rapid radiative adjustment to the forcing (at least in the $\mathrm{CO}_{2}$ forced simulations) and is thus not controlled by $\Delta \mathrm{T}_{\mathrm{S}}$. By subtracting this rapid adjustment from $\alpha_{\text {str }}$, we obtain the "pure" stratospheric temperature feedback $\alpha^{*}{ }_{\text {str }}$ As a result, we can transfer the feedback analysis to the stratosphere adjustment framework, where we can try to explain variations in stratosphere adjusted climate sensitivity $\lambda_{\text {adj }}$. For the forcings considered in this study, changes in $\alpha^{*}$ str are so small that they do not significantly contribute to the changes in the feedbacks' sum.

For the simulations with a large increase in $\mathrm{CO}_{2}$ $(2 \times \mathrm{CO} 2$ and $4 \times \mathrm{CO} 2)$, we can identify the physical cause for variations in $\lambda_{\text {inst }}$ and $\lambda_{\text {adj. }}$. For changes in $\lambda_{\text {inst, }}$, the main physical causes can be found in the stratospheric temperature, water vapour and cloud feedback. For changes in $\lambda_{\text {adj }}$, the main physical causes are water vapour and cloud feedback.

For the comparison of $\mathrm{CO}_{2}$ and non- $\mathrm{CO}_{2}$ increase simulations with a forcing of around $1 \mathrm{Wm}^{-2}$, we can identify the physical causes for variations in $\lambda_{\text {inst. }}$. The responsible feedbacks are the Planck, albedo and stratospheric temperature feedback. The cloud feedback may contribute as well to the variations in $\lambda_{\text {inst }}$, but the large statistical variability of the cloud feedback does not convincingly support this conclusion. If we remove the stratosphere adjustment from the feedback analysis (by subtracting the stratospheric temperature adjustment part from $\alpha_{\text {str }}$ ), the feedbacks' sum is not distinguishable on the required significance level anymore. Hence, the attempt to explain the origin of the 
variations in $\lambda_{\text {adj }}$ does not yield a convincing result. This highlights the difficult issue of scaling the forcing: in this case $1 \mathrm{Wm}^{-2}$ is obviously not large enough.

Hansen et al. (1997), among many others, indicated that radiative flux changes at the tropopause, rather than at TOA, are the most reasonable measure to estimate the impact of a perturbation on troposphere and surface temperature. The same arguments hold for radiative feedbacks (Geoffroy et al. 2014). The interpretation of the feedback's impact may strongly differ when the feedback is considered at TOA or at the tropopause. For example, for the $2 \times \mathrm{CO} 2$ simulation, the stratospheric water vapour feedback contributes only $2 \%$ to the total $\alpha_{\mathrm{q}}\left(2.01 \mathrm{Wm}^{-2} \mathrm{~K}^{-1}\right)$ at TOA and $15 \%$ of the total $\alpha_{\mathrm{q}}\left(2.42 \mathrm{Wm}^{-2} \mathrm{~K}^{-1}\right)$ at the tropopause. Thus, the small contribution of the stratospheric water vapour feedback to $\alpha_{\mathrm{q}}$ at TOA underestimates the importance of this feedback for the tropospheric response to a forcing (Stuber et al. 2005; Heckendorn et al. 2009; Solomon et al. 2010).

The radiative balance at the tropopause is shown in Fig. 8 (to be compared with Fig. 3 for TOA). The instantaneous radiative forcing (normalized by $\Delta \mathrm{T}_{\mathrm{s}}$ ) and the feedback parameters are larger at the tropopause than at TOA. It is obvious from Fig. 8 that forcing and feedbacks are less balanced at the tropopause than at TOA (Fig. 3). This leaves a residuum of the order of $0.12 \mathrm{Wm}^{-2} \mathrm{~K}^{-1}$, more than twice as large as at TOA. This larger residuum at the tropopause is physically plausible because ingoing and outgoing radiation at the tropopause does not need to be balanced. Sensible and latent heat fluxes contribute to the global energy budget at the tropopause (see also Gregory et al. 2004). An external forcing may also perturb the contribution of these fluxes. Thus, it will be more difficult to relate climate sensitivity changes to feedback changes at the tropopause.

\section{Conclusions and outlook}

According to our results, an attempt to uncover individual feedback processes which control climate sensitivity and efficacy variations for different types and strengths of radiative forcings is promising. The PRP method can be extended down to forcings of $1 \mathrm{Wm}^{-2}$, which still provides the potential to identify significant feedback changes. However, for feedbacks which show a high statistical variability (such as the cloud feedback) the limits of this method are reached. The feedback analysis indicates that for a set of $\mathrm{CO}_{2}$ increase simulations mainly the water vapour and the cloud feedback are responsible for variations in climate sensitivity. The reduced efficacy of ozone perturbations, induced by enhanced $\mathrm{NO}_{\mathrm{x}}$ and $\mathrm{CO}$ surface emission (compared to $\mathrm{CO}_{2}$ perturbation of similar forcing magnitude), is influenced by significant changes in the Planck and albedo feedback. We further assume that the cloud feedback plays an important role as well, although its statistical significance is not convincing.
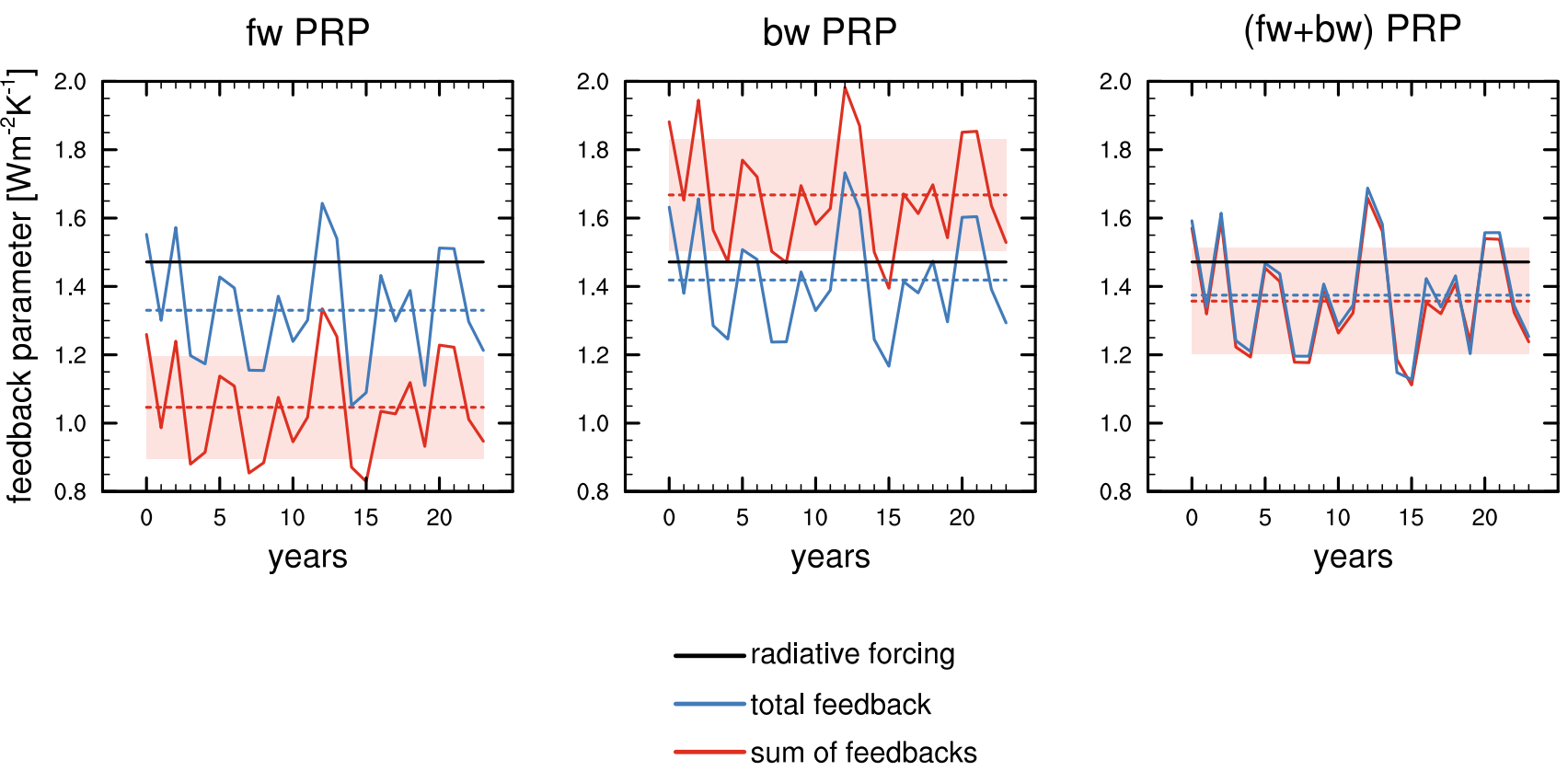

Fig. 8 Additivity of feedbacks at tropopause. As Fig. 4, but the absolute value of instantaneous radiative forcing $\mathrm{RF}_{\text {inst }}\left(\right.$ normalized by $\Delta \mathrm{T}_{\mathrm{s}}$ ), total feedback $\alpha$ and feedbacks' sum $\sum \alpha_{i}$ are calculated by flux changes at the tropopause 
From previous evidence on statistical uncertainty we have concluded that the effective radiative forcing concept is not well suited to relate climate sensitivity changes to feedback changes for forcings of around $1 \mathrm{Wm}^{-2}$. For such small forcings, the statistical uncertainty of the various parameters is too high. Thus, we have preferred to use the more conventional definition of radiative forcing and climate sensitivity based on the concept of the stratosphere adjustment. However, this made the interpretation of the results more difficult. The climate sensitivities are deduced from the stratosphere adjusted radiative forcing at the tropopause, but the feedbacks are based on instantaneous radiative flux changes at TOA. This difficulty could be solved by introducing a dedicated stratospheric temperature feedback which is separated from the tropospheric Planck and lapse rate feedbacks. However, it is obvious that the larger part of the stratospheric temperature feedback is related to rapid adjustments to the forcing rather than controlled by changes in the surface temperature.

Advancements in the methodology applied in this study are certainly possible. Longer equilibrium simulations or ensembles of simulations (for methods involving regression analysis of spin-up phases) rather than only one simulation for each forcing type would give better signal to noise ratios (Forster et al. 2016). An attempt to include the method of stratospheric temperature adjustment into the PRP tool may also be worthwhile. It would attribute stratospheric temperature changes induced by water vapour and cloud feedback to the respective feedbacks. This would considerably improve the interpretability of radiative feedbacks and the consistency in explaining efficacy differences.

\begin{abstract}
Acknowledgements This work has been carried out in the framework of the project "Verkehrsentwicklung und Umwelt" funded by DLR. The climate model simulations were part of the second author's $\mathrm{PhD}$ thesis, while the feedback analysis was performed in the framework of the first author's master thesis, both at the Ludwig-Maximilians-Universität München. Daniel Klocke made his PRP analysis code available for application and further modification, a considerable facilitation that we gratefully acknowledge. Advice given by Profs. Johannes Quaas, Robert Sausen and Bernhard Mayer has fostered this study, so did very helpful discussions with Johannes Mülmenstädt, Patrick Jöckel and Karoline Block. We used the NCAR Command Language (NCL) for data analysis and to create some of the figures of this study. NCL is developed by UCAR/NCAR/CISL/TDD and available on-line: doi: 10.5065/D6WD3XH5. The equilibrium climate change simulations were performed on the computer systems provided by the Deutsches Klimarechenzentrum (DKRZ).
\end{abstract}

Open Access This article is distributed under the terms of the Creative Commons Attribution 4.0 International License (http:// creativecommons.org/licenses/by/4.0/), which permits unrestricted use, distribution, and reproduction in any medium, provided you give appropriate credit to the original author(s) and the source, provide a link to the Creative Commons license, and indicate if changes were made.

\section{References}

Aires F, Rossow WB (2003) Inferring instantaneous multivariate and nonlinear sensitivities for the analysis of feedback processes in a dynamical system: lorenz model case study. Q J R Meteorol Soc 129:239-275

Allan RP, Ramaswamy V, Slingo A (2002) Diagnostic analysis of atmospheric moisture and clear-sky radiative feedback in the hadley centre and geophysical fluid dynamics laboratory climate models. J Geophys Res 107:4329

Andrews T, Forster PM (2008) $\mathrm{CO}_{2}$ forcing semi-direct effects with consequences for climate feedback interpretations. Geophys Res Lett 35:L04802

Andrews T, Gregory JM, Webb MJ, Taylor KE (2012) Forcing feedbacks and climate sensitivity in CMIP5 coupled atmosphere-ocean climate models. Geophys Res Lett 39:L09712

Berntsen TK, Fuglestvedt JS, Joshi MM, Shine KP, Stuber N, Ponater M, Sausen R, Hauglustaine DA, Li L (2005) Response of climate to regional emissions of ozone precursors: sensitivities and warming potentials. Tellus 57B:283-304

Block K, Mauritsen T (2013) Forcing and feedback in the MPIESM-LR coupled model under abruptly quadrupled $\mathrm{CO}_{2}$. J Adv Model Earth Syst 5:679-691

Boer GJ, Yu B (2003) Climate sensitivity and response. Clim Dyn 20:415-429

Bony S, Colman R, Kattsov VM, Allan RP, Bretherton CS, Dufresne JL, Hall A, Hallegate S, Holland MM, Ingram W, Randall DA, Soden BJ, Tseloudis G, Webb MJ (2006) How well do we understand climate feedback processes? J Clim 19:3345-3482

Cess R, Potter G, Blanchet J, Boer GJ, Ghan S, Kiehl J, LeTreut H, Li ZX, Liang XZ, Mitchell J, Morcrette JJ, Randall D, Riches M, Roeckner E, Schlese U, Slingo A, Taylor KE, Washington W, Wetherald R, Yagai I (1989) Interpretation of cloud climate feedback as produced by 14 atmospheric general-circulation models. Science 245:513-516

Colman R (2003) A comparison of climate feedbacks in general circulation models. Clim Dyn 20:865-873

Colman R, McAvaney B (1997) A study of general circulation model climate feedbacks determined from perturbed sea surface temperature experiments. J Geophys Res 102:19383-19402

Colman R, McAvaney B (2009) Climate feedbacks under a very broad range of forcing. Geophys Res Lett 36:L01702

Dietmüller S (2011) Relative Bedeutung chemischer und physikalischer Rückkopplungen in Klimasensitivitätsstudien mit dem Klima-Chemie-Modellsystem EMAC/MLO, DLR-Forschungsbericht 2011-19, Deutsches Zentrum für Luft- und Raumfahrt, Oberpfaffenhofen, Germany, ISSN 1434-8454, pp 124

Dietmüller S, Ponater M, Sausen R (2014) Interactive ozone induces a negative feedback in $\mathrm{CO}_{2}$-driven climate change simulations. J Geophys Res Atmos 119:1796-1805

Forster PM, Richardson T, Maycock AC, Smith CJ, Samset BH, Myhre G, Andrews T, Pincus R, Schulz M (2016) Recommendations for diagnosing effective radiative forcing from climate models for CMIP6. J Geophys Res. doi:10.1002/2016JD025320

Geoffroy O, Saint-Martin D, Voldoire A, Salas y Melia D, Senesi S (2014) Adjusted radiative forcing and global radiative feedbacks in CNRM-CM5, a closure of the partial decomposition. Clim Dyn 42: 1807-1818

Gregory JM, Webb M (2008) Tropospheric adjustment induces a cloud component in $\mathrm{CO}_{2}$ forcing. J Clim 21:58-71

Gregory JM, Ingram WJ, Palmer MA, Jones GS, Stott PA, Thorpe RB, Lowe JA, Johns TC, Williams KD (2004) A new method for diagnosing radiative forcing and climate sensitivity. Geophys Res Lett 31:L03205 
Hansen J, Lacis A, Rind D, Russell G, Stone P, Fung I, Ruedy R, Lerner J (1984) Climate sensitivity: analysis of feedback mechanisms. In: Hansen JE, Takahashi T (eds) Climate processes and climate sensitivity. American Geophysical Union, Washington DC, pp 131-163

Hansen J, Sato M, Ruedy R (1997) Radiative forcing and climate response. J Geophys Res 102:6831-6846

Hansen J et al. (2005) Efficacy of climate forcings. J Geophys Res 110:D18104

Heckendorn P, Weisenstein D, Fueglistaler, S, Luo BP, Rozanov E, Schraner M, Thomason LW, Peter T (2009) The impact of geoengineering aerosols on stratospheric temperature and ozone. Environ Res Lett 4:045108

Ingram WJ (2012) Water vapor feedback in a small ensemble of GCMs: two approaches. J Geophys Res 117:D12114

Jöckel P et al (2006) The atmospheric general circulation model ECHAM5/MESSy1: consistent simulation of ozone from the surface to the mesosphere. Atmos Chem Phys 6:5067-5104

Jonko AK, Shell KM, Sanderson BM, Danabasoglu G (2013) Climate feedbacks in CCSM3 under changing $\mathrm{CO} 2$ forcing. Part II variation of climate feedbacks and sensitivity with forcing. J Clim 26:2784-2795

Klocke D (2011) Assessing the uncertainty of climate sensitivity, University of Hamburg Reports on Earth system science 201195, Max-Planck-Institut für Meteorologie, Hamburg, ISSN 1614-1199, pp 88

Klocke D, Quaas J, Stevens B (2013) Assessment of different metrics for physical climate feedbacks. Clim Dyn 41:1173-1185

Marvel K, Schmidt GA, Miller RL, Nazarenko LS (2016) Implications for climate sensitivity from the response to individual forcings. Nat Clim Change 6:386-389

McCoy DT, Hartmann DL, Grosvenor DP (2014) Observed southern ocean cloud properties and shortwave reflection. Part II phase changes and low cloud feedback. J Clim 27:8858-8868

Meraner K, Mauritsen T, Voigt A (2013) Robust increase in equilibrium climate sensitivity under global warming. Geophys Res Lett 40:5944-5948

Mitchell JFB, Senior CA, Ingram WJ (1989) $\mathrm{CO}_{2}$ and climate: a missing feedback. Nature 341:132-134

Myhre G, Shindell D, Bréon FM, Collins W, Fuglestvedt JS, Huang J, Koch D, Lamarque JF, Lee D, Mendoza B, Nakajima T, Robock A, Stephens G, Takemura T, Zhang H (2013) Anthropogenic and natural radiative forcing. In: Stocker TF et al. (eds.), Climate change 2013: the physical science basis, contribution of working group I to the 5th assessment report of the IPCC. Cambridge University Press, Cambridge, pp 659-740

Randall DA, Wood RA, Bony S, Colman R, Fichefet T, Fyfe J, Kattsov V, Pitman A, Shukla J, Srinivasan J, Stouffer RJ, Sumi A, Taylor KE (2007) Climate models and their evaluation. In: Solomon S et al. (eds.), Climate change 2007: The physical science basis, contribution of working group I to the 4th assessment report of the IPCC. Cambridge University Press, Cambridge, pp 589-662

Ringer M, McAvaney BJ, Andronova N, Buja LE, Esch M, Ingram WJ, Li B, Quaas J, Roeckner E, Senior CA, Soden BJ, Volodin EM, Webb MJ, Williams KD (2006) Global mean cloud feedbacks in idealized climate change experiments. Geophys Res Lett 33:L07718
Roeckner E, Brokopf R, Esch M, Giorgetta M, Hagemann S, Kornblueh L, Manzini E, Schlese U, Schulzweida U (2006) Sensitivity of simulated climate to horizontal and vertical resolution in the ECHAM5 atmosphere model. J Climate 19:3771-3791

Shell KM, Kiehl JT, Shields CA (2008) Using the Radiative Kernel Technique to Calculate Climate Feedbacks in NCAR's Community Atmospheric Model. J Clim 21:2269-2282

Sherwood SC, Roca A, Weckworth TM, Andronova NG (2010) Tropospheric water vapor, convection, and climate. Rev Geophys 48:RG2001

Sherwood SC, Bony S, Dufresne JE (2014) Spread in model climate sensitivity traced to atmospheric convective mixing. Nature 505:37-43

Shindell T (2014) Inhomogeneous forcing and transient climate sensitivity. Nat Clim Change 9:274-277

Shine KP, Derwent RG, Wuebbles DJ, Morcrette JJ (1990) Radiative forcing of climate. In: Haughton JT, Jenkins GJ, Ephraums JJ (eds) Climate change: the IPCC scientific assessment, report prepared for IPCC by working group I. Cambridge University Press, Cambridge, pp 41-68

Shine KP, Cook J, Highwood EJ, Joshi MM (2003) An alternative to radiative forcing for estimating the relative importance of climate change mechanisms. Geophys Res Lett 30:2047

Shine KP, Highwood EJ, Rädel G, Stuber N, Balkanski Y (2012) Climate model calculations of the impact of aerosols from road transport and shipping. Atmos Ocean Opt 25: 62-70

Soden BJ, Held IM (2006) An assessment of climate feedbacks in coupled ocean-atmosphere models. J Clim 19:3354-3360

Soden BJ, Held IM, Colman R, Shell KM, Kiehl JT, Shields CA (2008) Quantifying climate feedbacks using radiative kernels. J Clim 21:3504-3520

Solomon S, Rosenlof KH, Portmann RW, Daniel JS, Davis SM, Sanford TJ, Plattner G-K (2010) Contributions of stratospheric water vapour to decadal changes in the rate of global warming. Science 327:1219-1223

Stuber N, Sausen R, Ponater M (2001) Stratosphere adjusted radiative forcing calculations in a comprehensive climate model. Theor Appl Climatol 68:125-135

Stuber N, Ponater M, Sausen R (2005) Why radiative forcing might fail as a predictor of climate change. Clim Dyn 24:497-510

Tan I, Storelvmo T, Zelinka MD (2016) Observational constraints on mixed-phase clouds imply higher climate sensitivity. Science 352:224-227

Vial J, Dufresne JF, Bony S (2013) On the interpretation of intermodel spread in CMIP5 climate sensitivity estimates. Clim Dyn 41:3339-3362

Wetherald RT, Manabe S (1988) Cloud feedback processes in a general circulation model. J Atmos Sci 45:1397-1416

Yoshimori M, Broccoli AJ (2008) Equilibrium response of an atmosphere-mixed layer ocean model to different radiative forcing agents: global and zonal mean response. J Clim 21:4399-4423

Zelinka MD, Klein SA, Taylor KE, Andrews T, Webb MJ, Gregory JM, Forster PM (2013) Contributions of different cloud types to feedbacks and rapid adjustments in CMIP5. J Clim 26:5007-5027 